\title{
The Effect of Electricity Load Management on the Operations of Small and Medium Enterprises: A Case Study of La-Nkwantanang Madina Municipality
}

\author{
Rahman Dunya $^{1 *} \quad$ Dongdong Chen ${ }^{1} \quad$ Ebenezer Appiah $^{2}$ \\ 1.College of Management, Sichuan Agricultural University, 611130, 211Huimin road, \\ Wenjiang, Chengdu, China \\ 2.Research Institute of Economics and Management, Southwestern University of \\ Finance and Economics, China
}

\begin{abstract}
Ghana has been experiencing frequent power cuts over the last ten years. The need to expand and diversify its generation capacity in order to improve supply security is key for development. This study explored the effects of electricity load management on the operation of small-scale enterprises, and examined the effectiveness of these enterprises' coping mechanisms. A cross-sectional survey design was adopted as well as the mixed approach research design. A total of 152 small scale traders were sampled from Madina in La-Nkwantanang Municipality in the Greater Accra Region. The study depicted that the recent load management is having adverse effect on the profitability of many SMEs owing to the coping mechanism measures such as retrenchment of workers, working at night, reduction in workers' salaries and use of generators they have adopted to lessen the impact of the frequent load management reported less effectiveness in resolving the challenges posed by load management. This paper advocate that, government should invest in solar energy to be a substitute power supply to the country during the dry season where there is constant sunlight which obviously will also reduce pressure on electricity plants. Broken and unbroken but old plants can be fixed or replaced by VRA and ECG to enable them work effectively as well as explore other energy technologies such as the thermal energy and the wind energy to restore constant power supply.
\end{abstract}

Keywords: electricity load management, small and medium enterprises

DOI: $10.7176 /$ RJFA/10-2-08

\subsection{Introduction}

Micro and small-scale industries (MSI) contribute significantly to employment creation, income and revenue generation, and overall poverty reduction in developing countries (Aremu \& Adeyemi, 2011). Kayanula and Quartey (2000) opine that, the MSI sector plays kingpin roles in driving developing countries' engines of growth. The Ghanaian economy is experiencing a severe energy crisis that hit the entire country since June 2006. This "energy crisis" necessitated the "embarrassing and expensive" load-shedding program of the Volta River Authority (VRA) that commenced in August 2006 and is still ongoing with no fixed date as to when it will end. Meanwhile, the adverse impact of the crisis has continued to be dreadful and unrelenting, escalating the operating costs of businesses and limiting production and hence output growth particularly in energy-sensitive sectors of mining and manufacturing all of which have serious implications for profits and employment as well as for government revenue targets. It is somewhat ambiguous that while the official assessment of the growth performance of the economy in 2006 acknowledges a "slowdown" in the growth performance of energysensitive sectors such as mining and manufacturing, the Electricity and Water sub-sector the source of the energy crisis is reported to be the lead driver of the overall real GDP growth rate of 6.2 percent registered for 2006, with an incredible output growth of 23.0 percent in 2006 over the output of 2005 . Complementary power generated from thermal plants with the intent of augmenting electricity supply in Ghana has not provided an antidote to the inadequate and unreliable supplies of electricity (Institute of Statistical, Social and Economic Research (ISSER, 2005). ISSER (2005) and Kumasi Metropolitan Assembly (KMA, 2010) assert that increasing population with corresponding inelastic supply of electricity are the major factors affecting the reliable supply of electricity for industrialization in Ghana. Compounding the problem is the inability of the Electricity Company of Ghana (ECG) to replace old transformers and loaders with new ones of higher capacities.

Given the rising production costs and loss of productive man-hours on account of the energy crisis, domestic prices could go up, though judging from the official inflation statistics this has apparently not happened yet. Business managers are reportedly constrained by fear of pricing themselves out of the market. This fear stems from the fact that the market is flooded with cheaper imported substitutes. Their customers may shift to the cheaper imports if prices of competing locally manufactured goods go up. Already, as may be seen in the downward revision of manufacturing sector growth rate in 2012, there has been some loss of price competitiveness of Ghanaian products on account of the real exchange rate overvaluation emanating from the disinflation monetary policy of the Bank of Ghana. As so often happens when the domestic currency is 
overvalued, non-traditional exports such as domestic manufactured goods could lose grounds in international markets while import-competing domestic products lose out to cheaper imports at home. Local manufacturing costs, as would be expected, have already risen as a result of the load management leading to significant increases in their cost build-up. The country's largest manufacturer, Unilever is said to be spending about US\$45,000 per month on energy generation (CEPA, 2007). Companies that use energy intensively, especially in the metals and plastic sub- sectors, are similarly reported to spend huge sums of money on fuel to run generators. There are reports quoting business surveys that production costs have raised by 20-30 percent. Wahome Steel in the metals sub-sector is reported to have cut production by 50 percent and sent 200 of its workers homes. Upon review of literature, it has come to the realization that much work have not been done quantitatively on the effects of electricity load management on the local economy with respect to the activities in Madina and this is what this study seeks to explore.

\subsection{Literature Review}

Load shedding is a measure of last resort to prevent the collapse of the power system country- wide. When there is insufficient power station capacity to supply the demand (load) from all the customers, the electricity system becomes unbalanced, which can cause it to trip out country-wide (a blackout), and which could take days to restore. As the difference between supply and demand becomes small, we refer to the system becoming "tight". This implies that action has to be taken to prevent the system from becoming unstable. Electricity Company of Ghana normally takes a sequence of steps to keep the system stable and to avoid load shedding. The steps include first asking large customers to reduce load voluntarily. However, if several power station units trip suddenly and unexpectedly, we may have to skip those steps and go straight to load shedding to prevent the system from becoming unstable. SMEs are defined differently by various institutions in Ghana; using different variables. For example, the National Board for Small Industries (NBSSI) defines it by using employment and capital assets of an enterprise. Based on those variables, small scale enterprise is one with not more than 9 workers, and has plant and machinery assets (excluding land, buildings and vehicles) not exceeding GHS 10 million (US\$5million). On its part the Ghana Enterprise Development Commission defines small business as one with capital assets not exceeding GHS10million (US\$5 million).

\subsection{The roles of SMEs to national development}

The role of SMEs a

s engines of endogenous development in local economy is increasingly recognized in development theory and has attracted the attention of policymakers.

O They add value to agricultural products and play crucial roles in the decentralized use and distribution of resources (Tacoli, and Satterhwaite, 2003).

O They augment government efforts to achieve economic growth and poverty reduction in rural and urban areas (African Development Bank, 2005). Wangwe (1999) argues further that SMEs tends to ensure balanced economic growth since they are concentrated in different parts of the country.

O They have been credited for introducing innovations into the market to serve as a catalyst for societal development. (Reijonen and Komppula, 2007).

According to UNCTAD (2001), a vibrant SME sector can also help to achieve a more equitable distribution of the benefits of economic growth by alleviating some of the problems associated with uneven income distribution. As a result, many development plans in developing countries have placed strong emphasis on the development of an entrepreneurial middle-class that create employment and has the potential to overcome institutional conditions that prevent growth in the local economy. For example, in Ghana, the Growth and Poverty Reduction Strategy (GPRS I \& II) identified SMEs as engines of growth, wealth creation and avenues for employment generation for its citizens.

In Ghana, a vibrant SME sector in the rural areas is very important since about $60 \%$ of the country's population reside in these areas where poverty is more pronounced. According to the Ghana Statistical Service (GSS) about $86 \%$ of the population living below the poverty line in Ghana can be found in the rural areas. Recognizing the critical role of the SMEs in poverty reduction, a number of existing institutions which have a mandate to promote industrialization in the local economy, have been strengthened to facilitate more economic change on the countryside. In order to build strong local economy, the government of Ghana has set up National Vocational Training Institutions (NVTI), established entrepreneurial development programs as well as favourable conditions for Micro Finance Institutions (MFIs) and other infrastructural services to encourage the growth and development of both informal and formal SMEs in the country.

Small and Medium Enterprises (SMEs) are important to the economy of Ghana. This is buttressed by the fact that the industrial and business sectors are dominated by a large informal sector. For instance, about $70 \%$ of the Ghanaian enterprises are micro to small sized and it is estimated that nearly $40 \%$ of Ghana's Gross National 
Income (GNI) is attributed to informal sector activity (Ghana Government, 2004). It is believed that small firms can more easily propel growth in the economy than the large ones due to their numbers and niches they occupy in the national economy (Ghana Government, 2004).

\subsection{Electricity Supply for Industries in Ghana}

Just like any other country, electricity is observed as a major tool for national development, vigorous efforts have been made to ensure that industries have access to reliable and affordable electricity in Ghana (NDPC,2008: p.182). Hydropower and imported fossil fuel are the main energy sources used to generate electricity in Ghana (fossil fuel is used to generate thermal electricity). In the year 2010, the amount of electricity generated amounted to $10166 \mathrm{GWh}$, hydro-electricity accounted for $6995 \mathrm{GWh}$ and the rest $(3171 \mathrm{GWh})$ from thermal electricity. Ghana has a combined capacity of both hydro and thermal electricity installation of 1960MW; electricity demand as at 2010 was1400MW and this demand have a growing rate of $10 \%$ per annum (Ministry of Energy, 2010). The table below shows the electricity power plants in Ghana.

Table1. Electricity power plants in Ghana

\begin{tabular}{|c|c|}
\hline Hydro Power Plants & Thermal Power Plants \\
\hline$\bullet$ Akosombo Hydro Power Plant & $\bullet$ Takoradi Power Company (TAPCO) \\
\hline$\bullet$ Kpong Hydro Power Plant & $\bullet$ Takoradi International Company (TICO) \\
\hline Bui Hydro Power Plant & $\bullet$ Mines Reserve Plant (MRP) \\
\hline & $\bullet$ Tema Thermal 1 Power Plant (TT1PP) \\
\hline & $\bullet$ Tema Thermal 2 Power Plant (TT2PP) \\
\hline
\end{tabular}

Source: Authors' construct 2018

Since electricity plays an important economic role, the nexus between economic development and access to electricity from time to time has raised debates on the inadequacies and inefficiencies existing in the Ghanaian energy market. These inadequacy and inefficiency have serious impacts on profit margins of businesses, employment and as well as government revenues. The formal Ghanaian energy market can be described as a centralized market which is mainly controlled by government institutes.

\begin{tabular}{|c|c|c|c|}
\hline $\begin{array}{c}\text { Generation and } \\
\text { supply }\end{array}$ & Transmissio & Distribution & End users \\
\hline \multirow{2}{*}{$\begin{array}{c}\text { VRA } \\
\text { Electricity }\end{array}$} & \multirow{2}{*}{ GRIDCO } & NED (VRA) & - Industries \\
\hline & & $\begin{array}{l}\text { Electricity } \\
\qquad \text { ECG }\end{array}$ & $\begin{array}{c}\text { - Residential } \\
\text { - Non-residential }\end{array}$ \\
\hline
\end{tabular}

Figure 1: Institutions Responsible for Supply of Electricity

Source: Adopted from GRIDCo, 2010

The Public Utility Regulatory Commission (PURC) and the Energy Commission are the bodies responsible for regulating the electricity supply industry (Ministry of Energy, 2010). PURC is the body mandated by government to set electricity tariff; the tariffs are normally set in consultation with key stakeholders made up of the generators, distributors and the representatives of major consumers (Energy Commission Ghana, 2006). The Energy Commission on the other hand is responsible for technical regulation and advising the Ministry of Energy on energy planning and policies. The electricity supply system in Ghana is divided into bulk electricity (transmission level) and final electricity (distribution level) (ibid). A block end user tariff system is used in Ghana and this is classified largely into industry, commercial (non-residential) and 5.2-8.2 US cents per unit; this tariff rate is relatively lower compared to other neighbouring countries like Benin and Togo.

\subsection{Challenges/problems facing the energy sector in Ghana}

Issues of energy security constantly threaten Ghana's economy; these issues stem from challenges facing the energy sector of Ghana. The energy challenges in Ghana are mainly centralized on the supply side of the sector, thus undermining accessibility, affordability and reliability of energy supply. The development framework of Ghana is governed by two documents; The Ghana Poverty Reduction Strategy and the Coordinated Program of Economic and Social Development (AmoakoTuffour and Armah, 2008). The objectives of both frameworks are to provide strategies to boost economic growth and reduce poverty in Ghana. A critical factor for the successful realization of these growth objectives will be the ability to meet the energy needs of the country (AmoakoTuffour and Armah, 2008). In order to meet local demand of fuel, the economy of Ghana is now over dependent on the importation of crude oil to the extent that, crude oil imports represent a large portion of Ghana's 
international trade transactions. In 2001, crude oil importation accounted for approximately 80 percent of the trade deficit (Amoako-Tuffour and Armah, 2008). Between the periods of 2000 and 2004, the volatile prices of crude oil also increased the cost of crude oil importation from US\$280 million to over US\$ 500 million respectively (Energy Commission Ghana, 2006a); thus, the economy of Ghana is very sensitive to the price of crude oil. On a downside, an increase in the energy demand of Ghana (due to economic growth and population increase), can further increase the vulnerability of the country's economy to the volatile price of crude oil and subsequently lead to an economic instability. Excessive use of wood fuels by the rural communities due to their lack of access to other forms of energy and poverty is a primary cause of deforestation in Ghana. Energy losses about $26 \%$ of the total primary supply in 2000 and increased to about $30 \%$ in 2004 as a result of inefficient conversion, distribution and use of energy resources (Energy Commission Ghana, 2006a).

Lack of capital is also major challenge. Solar energy and other renewable source have a high potential of providing energy especially to rural locations in the country but these resources are barely exploited due to lack of funds to afford the systems of conversion. A large fraction of Ghana's electricity is generated from two hydroelectric dams (approximately $70 \%$ of actual electricity generated), as a result, the Ghanaian economy faces severe electricity crisis when there is low water inflow into the hydro-electric dams. In recent time Ghana has experienced three drought-related electricity crises; in 1998, 2002 and 2006 all resulting in an expensive load shedding program to cut down and manage the demand load of the country. This severe series of drought related electricity crisis has resulted in the shutting down of companies and industries in Ghana.

\subsection{The effect of electricity to SME's development}

The Centre for Policy Analysis (CEPA, 2007) identified that the 2007 power rationing exercise in Ghana resulted in increased local manufacturing costs. Concha Velasquez and Pichler (2010) also reiterated that sufficient and affordable supply of energy (electricity) has had a decisive significance for economic activities and economic growth can or may be restricted by resource energy. Since a country's economic growth is a composite of economic activities of small and medium enterprises, the less cost they have to tolerate, the better a country's chance at harnessing their input towards greater levels of gross domestic product and growth. Okpara (2011) as cited in Kapepiso (2015) consents that; SMEs can contribute immensely towards economic growth and poverty reduction. Arinaitwe (2006) found that, the rate at which SMEs fail in developing countries is higher than in the developed world. Irjayanti and Azis (2012) found that, as a result of free market system, Indonesian SMEs were fighting stiff competition from foreign products and firms who have the ability to produce better quality products while high cost of energy accounted for $62 \%$ of respondents' identification of barrier factors against the SMEs country. A research carried out by

Data Bank Ghana Limited estimated that, Ghana's economy could lose about1.4 billion dollars due to electric power crisis on manufacturing, services and informal sector of which SMEs play a very pivotal role. Therefore, to forestall these loses there is urgent need to better structure the production and distribution of electrical power so as to enhance the chances of growing the economy and achieving the goals of any development initiatives. Alam (2013) found that, there was causality for electric power consumption and foreign direct investment as well as economic growth.

Confederation of Tanzanian Industries (CTI, 2011) argues that Tanzania's manufacturing sector also experiences unreliable, intermittent power supply, frequent rationing and outages and such occurrences cause manufacturers to experience poor service quality, unplanned power stoppages and interruptions, voltage fluctuations, phase failures and unbalanced voltages.

Burlando (2010) also identified that a month-long blackout in Zanzibar-Tanzania caused a large decline in household income among those employed in occupations that required electricity and as a result, those workers had to reduce work hours by an average of $8 \%$ per day during the blackout period. The August 14, 2003 blackout that occurred in New York, Michigan, Massachusetts, Ohio,

New Jersey, Connecticut and Vermont all in the United States of America, caused an estimated loss of \$6.4 billion (Anderson and Geckil, 2003). Tambunan (2004), while high production capacity deficiency, limitation in sales and high labour costs accounted for $21 \%, 36 \%$ and $18 \%$ respectively, electricity accounted for $62 \%$ been the major barrier to SME development in Indonesia. Small and Medium Enterprise sectors accounted for $99 \%$ of businesses in Indonesia making them the most significant contributors to economic development (Irjayanti and Azis, 2013). Wang (2002) revealed that a power interruption lasting between 1 and 4 seconds can result in a loss of more than US\$3 to US\$10 million of damage to their properties.

\subsection{The effects of load shedding on the operations of SMEs}

According to Lineweber \& McNulty (2001), businesses could suffer from two types of load shedding; poor quality, and power outages. Poor quality refers to the fluctuations in voltage, which could result in severe damage to machinery and equipment, and a corresponding high cost of frequent repair and replacement. Power outages relates to a complete loss of power, lasting from one second to hours. The extent of power outages can 
be measured by their frequency, their duration, or firms ${ }^{\text {ee }}$ self-assessment of the severity of the issue or the associated losses (Lineweber and McNulty, 2001; Jyoti et al., 2006). Power outages affect both developed and developing countries. This is shown in the relatively vast literature that covers firms from both parts of the world. However, the extents of their magnitude, their frequency, as well as their underlying causes differ from one group to the other. Developing countries turn out to be more affected by insufficient provision of electricity power, and within these countries, SMEs appear to suffer the most (Lee and Anas, 1992; Steel and Webster, 1991). Electricity is a significant component of virtually any production process. As such, limited supply has the potential to, directly and/or indirectly; affect the economic activities of firms. In documenting such a crucial economic role of energy, a common approach in the literature is to measure the output loss associated with electricity outages. One of the analytical frameworks used is a production function in which electricity contributes directly to firms' output as a separate input, and indirectly as a determinant of the extent to which other direct inputs such as capital equipment is used (Adenikinju, 2005).

An alternative approach, a subjective method, is based on self-assessment by which surveys ask firms to quantify the loss they incur due to power outages. This approach relies on the assumption that firms well positioned to provide relatively accurate valuation of how much it cost them to replace more frequently or to repair damaged machinery or equipment, or to assess the lost output due to idled inputs. However, many biases can plague the outcome, since firms may have the tendency to overestimate the incurred costs, hence, overemphasizing the constraint that electricity poses to their business activity (Uchendu, 1993). These analytical frameworks have generated different estimates of the cost of electricity shortages to firms. The literature documents a wide range that varies across countries, industries, and firms. Caves et al. (1992) suggests that the costs range between $\$ 1.27$ and $\$ 22.46$ per $\mathrm{kWh}$, and that the costs to SMEs were, systematically, higher compared with those of large businesses. These costs also appeared to be higher compared with those incurred by households, for whom the numbers varied between $\$ 0.02$ and $\$ 14.61$ per kWh. Matsukawa and Fuji (1994) estimated the cost to Japanese firms at $\$ 118$ to $\$ 149$ per $\mathrm{kWh}$. These large differences appear to be related to the various specificities of countries and industries, as well as the methodological approaches used in the estimation of the costs of power outages. To deal with this apparent sensitivity, we will try to combine various approaches of measuring the incidence of power outages. Both objective and subjective measures of power outages will be used alternatively, that is, the frequency, and the length of electricity outages, and firms ${ }^{\text {ee }}$ self-assessment of the extent to which electricity is an obstacle to firms' activity.

\subsection{Methodology \\ 3.1 Research design}

This study adopts the cross-sectional survey design. This type of design is employed in this study due to its merit of helping the researchers in collecting original data from a large population which is difficult to observe. In addition, the cross-sectional survey design is a first-rate tool for measuring the features/characteristics of large populations. Under the research design, the research approach adopted was the Mixed Approach. This implies that the study would embrace both Quantitative and Qualitative paradigms. In terms of quantitative research, the focus is on explanatory studies and its findings will be expressed in numerical form. The Qualitative research on the other hand considers descriptive studies and its findings will be expressed in statement form; which will help to get in-depth knowledge and understanding about how the current load management has affected the Small and Micro Enterprises in Madina. A semi-structured questionnaire has been used in asking responses from SMEs on how the current load management has affected their business operations. Also, face-to-face interviews with respondents was undertaken to know the quantity consumed on electricity.

\subsection{Study Population}

The population of this study includes barbers, hair dressers, milling factories, printing press, restaurants, cold stores and super markets located at Madina. It comprises of the total number of elements in the study area from which the sample would be taken. The absence of data on the total population of the small-scale enterprises in the suburb remained a limitation.

\subsection{Sampling Frame}

The sampling frame for this study was the list of all the small scales businesses in Madina. 
Table2. Types of SMEs and Their Population

\begin{tabular}{lc}
\hline Type of Enterprise & Total Population \\
\hline Printing Press & 46 \\
Barbering Shops & 45 \\
Supermarkets & 54 \\
Milling & 14 \\
Cold Stores & 15 \\
Hair dressers & 44 \\
Food Sellers & 26 \\
\hline
\end{tabular}

Source: Authors' Construct, 2018

\subsection{Sample Size}

A total of 244 petty traders constitute the population for the study. Adopting on the selection of sample size, Agyedu et al., (2007) advised that the sample must be 10 or $15 \%$ of the total population. That notwithstanding, Huang and Bell (2004) advanced instructively that "the number of subjects in an investigation should necessarily depend on [among others] the length of "time" and the "means". A sample size of one hundred and fifty-two (152) which constitute $62.3 \%$ of the population was selected as sample for the study. The one hundred and fiftytwo was then distributed proportionally for all the seven categories of SMEs. The sample size determination method used for totalling the sample size is given as; $n=N / 1+N\left(d^{2}\right)$ where $n$ is the sample size for the study population; $\mathrm{N}$ is the sample frame while $\mathrm{d}$ is the error margin $(5 \%$ error margin is considered since it is widely regarded as the appropriate error margin for social researches).

$\mathrm{n}=$ sample size

$\mathrm{N}=$ sample frame

$\mathrm{d}=$ error margin

$$
\mathrm{n}=\frac{\mathrm{N}}{1+\mathrm{N}\left(\left(\mathrm{d}^{2}\right)\right)}
$$

Table3. Number of SMEs by Type and Proportion of the Sample Size

\begin{tabular}{|l|c|c|c|}
\hline Petty Traders & Population & Percentage & $\begin{array}{c}\text { Proportion to the Sample } \\
\text { Size }\end{array}$ \\
\hline Printing Presses & 46 & 18.85 & 29 \\
\hline Barbering Shops & 45 & 18.44 & 28 \\
\hline Super Markets & 54 & 22.13 & 34 \\
\hline Millings & 14 & 5.74 & 9 \\
\hline Cold Stores & 15 & 6.15 & 27 \\
\hline Hair Dressers & 44 & 18.03 & 16 \\
\hline Food Sellers & 26 & 10.66 & $\mathbf{1 5 2}$ \\
\hline Total & $\mathbf{2 4 4}$ & $\mathbf{1 0 0}$ & 9 \\
\hline
\end{tabular}

Source: Authors' construct 2018

\subsection{Data sources and method of data collection}

Data used in this study were from both primary and secondary sources. The primary data were obtained through direct observation and in-personal interviews with the units of inquiry. The researcher adopted closed-ended and open-ended questions in soliciting information from the respondents to facilitate analysis of data. Open-ended questions give opportunity to respondents to freely express their opinions and ideas on the topic under study. The secondary data were collated from journal articles, working papers, research reports, book chapters, conference proceedings, government policy documents and theses. The secondary data sources provided understanding into the measures to put in place to restore constant power so as to ensure continuity of business operations.

\subsection{Procedures for data analyses and presentation}

The data, which will be obtained in the form of responses from respondents, will be processed using Statistical Package for Social Sciences (SPSS). The collected data will be collected, analysed and presented in tables. First, the data collected will be edited, coded and analysed. The coding helps the researcher to remove items, which are not completed and enable numbers to be assigned to the various responses to the items of the questionnaires. In case of the interview schedule, the responses to the various items will be triangulated. The statistical tool that will be used for the study is the descriptive statistics. Frequencies, percentages and percentage rank will be used to measure the directions of the responses. 
Table4. Socio-demographic characteristics of respondents.

\begin{tabular}{|c|c|c|c|}
\hline & & $\mathrm{N}$ & $\%$ \\
\hline \multirow{3}{*}{ Gender } & Male Female & 71 & 46.70 \\
\hline & & 81 & 53.30 \\
\hline & Total & 152 & 100 \\
\hline \multirow{4}{*}{ Age } & Below 30years & 45 & 29.30 \\
\hline & $31-40$ years & 81 & 53.30 \\
\hline & $41-50$ years & 16 & 10.70 \\
\hline & Above 50 years & 10 & 6.70 \\
\hline \multirow{8}{*}{ Level of Education } & Total & 152 & 100 \\
\hline & No. Formal Education & 12 & 8.00 \\
\hline & Primary & 8 & 5.30 \\
\hline & Junior High School (JHS) & 28 & 18.70 \\
\hline & Senior High School (SHS) & 53 & 34.70 \\
\hline & University & 8 & 5.30 \\
\hline & Others & 43 & 28.00 \\
\hline & Total & 152 & 100 \\
\hline \multirow{3}{*}{ Type of business ownership } & Sole Proprietorship & 130 & 85.30 \\
\hline & Partnership & 22 & 14.70 \\
\hline & Total & 152 & 100 \\
\hline \multirow{7}{*}{ Years of Existence } & $1-5$ years & 77 & 50.70 \\
\hline & $6-10$ years & 24 & 15.80 \\
\hline & $11-15$ years & 16 & 10.50 \\
\hline & $16-20$ years & 16 & 10.50 \\
\hline & $21-30$ years & 19 & 12.50 \\
\hline & Total & 152 & 100 \\
\hline & Firm & $\begin{array}{c}\text { No. employees } \\
\text { (Mean) }\end{array}$ & Rank \\
\hline \multirow{7}{*}{ Employment Status } & Printing Shops & 8 & 2nd \\
\hline & Supermarkets & 4 & 4th \\
\hline & Barbering Shops & 4 & 4th \\
\hline & Hairdressing & 6 & $3 \mathrm{rd}$ \\
\hline & Milling & 3 & 6th \\
\hline & Food Vendors & 9 & $1 \mathrm{st}$ \\
\hline & Cold Stores & 3 & 6th \\
\hline
\end{tabular}

Source: Authors' Field Survey, 2018.

From table 4 above, it could be seen that $53.3 \%$ were females while $46.7 \%$ were males. This analysis shows that the SMEs operators in Madina are dominated by females.

\subsubsection{Age distribution of respondents}

It can be deduced from table 4 that, 30 years and below respondents represents $29.3 \% ; 53.3 \%$ of them were between 31 to 40 years; 50 years were $10.7 \%$, and those who were between 50 to 60 years were $6.7 \%$ of the respondents. The study discovered that majority of the operators of SMEs at Madina in La-Nkwantanang Madina Municipality were youthful and very energetic since most of the respondents were 40 years and below.

\subsubsection{Level of education}

The statistics in table 4 above shows the analysis of the levels of education of the respondents. It shows that 12 of the respondents constituting 8\% had no formal education, 5.30\% (8) and 18.7\% (28) Primary and Junior High School leavers respectively. That aside, 43 of them constituting 28\% had other qualifications such as Middle School Leavers' Certificate and Diploma in Computing/Information Technology, and 8 respondents representing $5.30 \%$ were University graduates However, majority $34.70 \%$ (53) of the respondents as at the time of the research were Senior High School (SHS) leavers.

\subsubsection{Types of business ownership}

The results of the study indicate that $85.3 \%$ of the firms reported that they were sole proprietorship whereas $14.7 \%$ of the firms indicated that they were Partnership. Also, none of the firms were joint venture as it reported zero percent. This implies that all the firms were solely owned - managed and controlled by their owners. This result affirms the finding of a study conducted by Amponsah (2010) that suggested all the micro and small-scale enterprises were managed and controlled by their owners. Table 4 gives respective tabular representation of the 
types of business ownership of the SMEs in Madina in La-Nkwantanang Madina Municipality.

\subsubsection{Years of existence}

The study revealed that SMEs who had existed between 1-5 years were 50.7 percent; $15.8 \%$ of the firms existed between 6-10 years, whilst $10.5 \%$ had been operated between 11 to 15 years as same as between $16-20$ years. Also, $12.5 \%$ of the firms indicated that their businesses had existed between $21-30$ years. The average year of experience is 9. With this year of existence, owners of the SMEs are therefore permanent workers in their respective firms.

\subsubsection{Number of employees}

The results show that the average number of workers employed by supermarket was 4 , the cold stores employed 3 workers on the average, and the hair dressing saloons engaged 6 workers on the average. Similarly, food vendors and printing shops averagely employed 9 and 8 respectively. Also, milling factory has average workers of 3 .

\subsection{The uses of electricity}

The study identified that all the micro and small-scale enterprises located within Madina in the La-Nkwantanang Madina Municipality depended on electricity supplied by VRA through ECG for their operations. The food vendors used electricity in freezing their fishes, vegetables and sachet water. The supermarkets used electricity to freeze alcoholic and non-alcoholic drinks and bottled water. Similarly, hairdressers used electricity to operate their drying machines to dry hairs of customers whereas barbers used electricity to operate their hair trimmers to shave and cut hairs of customers. Cold store operators also used electricity to power their refrigerators to produce and preserve iced blocks and meat respectively. The milling factories within the Madina market also used electricity to drive their mills to process corn, cassava, flour and vegetables. Printing shops within and around the University of Professional Studies, Accra used electricity to power their computers, photocopiers and printers to print customers' works (publications, posters, etc).

\subsection{Hours of electricity needed}

The researchers wanted to find out how many hours of electricity required by the firms, in carrying out their day to day activities. The study identified that electricity is constantly required by all the cold stores operators to keep their products preserved. As the nine cold stores operators expressed that they required a 24-hour constant supply of electricity to keep fish, meat and water frozen. Again, the study identified that though the other enterprises required a constant supply of electricity, it was needed only during their working hours. The printing shops, hair dressers, and food vendors needed a constant supply of electricity to power their equipment.

As indicated in figure 2 below, milling required 12 hours constant supply of electricity to power their mills. Similarly, the supermarkets, and barbering shops required 14 hours, and 13 hours respectively of constant supply of electricity for their operations. All the enterprises indicated that they do not get constant supply of electricity due to power outages. This may be so as the ECG per the current electricity load management schedule can only supply them with 12 hours of electricity. The figure below shows pictorial representation of how many hours of electricity the enterprises needed so as to carry out their daily business activities smoothly.

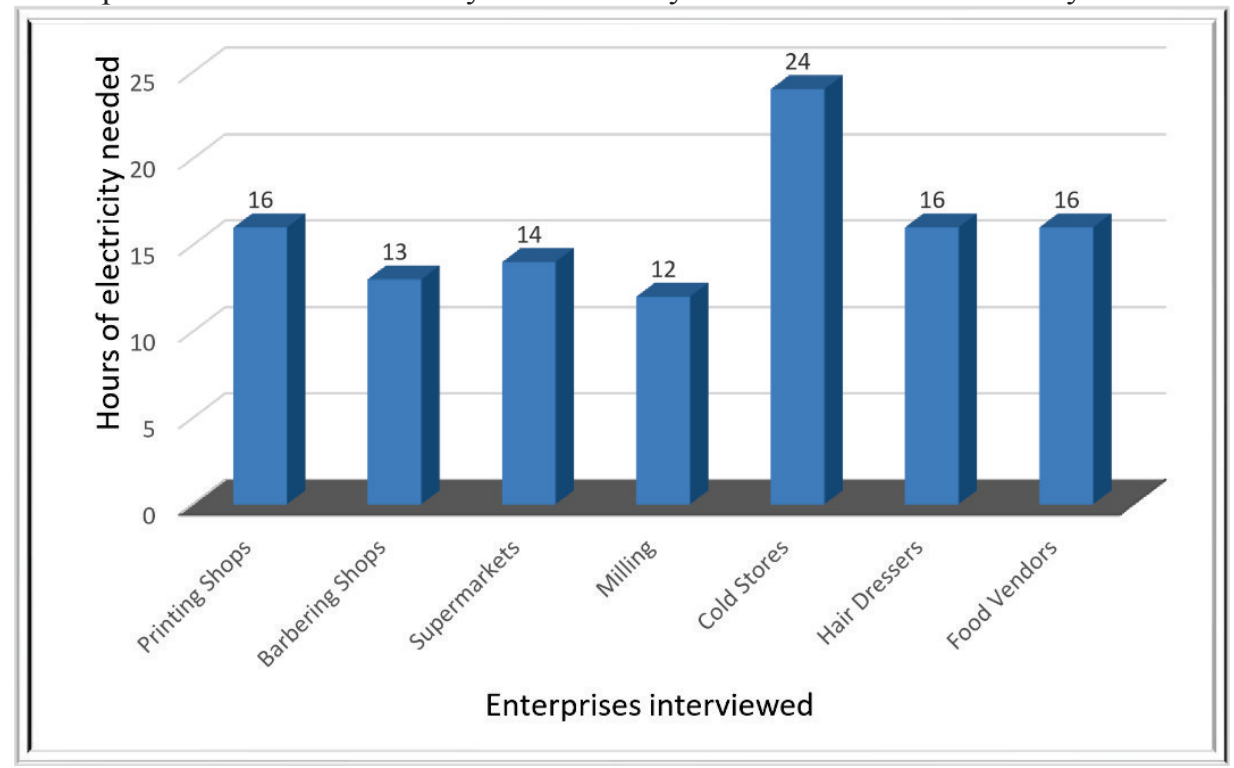

Source: Field Survey, 2018

Figure2. Hours of electricity needed 


\subsection{Ways of coping with frequent electricity load management}

Due to the adverse effects of the recent load management on the operation of the enterprises, the researchers intended to ascertain the coping mechanisms that have been adopted by the various small-scale businesses at Madina in La-Nkwantanang Madina Municipality. The study identified that $72.4 \%$ of the printing shop operators, $53 \%$ of the supermarket, $50 \%$ of the barbers, $85 \%$ of the hair dressers, and $56.25 \%$ of the food vendors indicated they used generators in times of power cut.

From table 5, all the milling factories and cold stores operators reduced their workers' salaries in order to minimize the adverse effects of interrupted supply of electricity on the operations of their daily activities. Further, $13.8 \%$ of the printing shop operators, $35 \%$ of the supermarket operators, $20 \%$ of the barbers and $12.5 \%$ of the food vendors have decreased the salaries of their workers during power cuts periods. However, the researchers also discovered that $12 \%$ of the supermarket operators, $13.8 \%$ of the printing shop operators, $31.25 \%$ of the food vendors, $15 \%$ of hairdressers, and $30 \%$ of the barbers as at the time of the study worked at night.

Table5. Ways of coping with frequent electricity load management

\begin{tabular}{|l|l|l|l|l|l|l|l|l|}
\hline & \multicolumn{2}{|l}{ Use of generators } & \multicolumn{2}{l|}{$\begin{array}{l}\text { Reduce workers } \\
\text { salaries }\end{array}$} & \multicolumn{2}{l|}{ Work at night } & \multicolumn{2}{l|}{ Total } \\
\hline & F & \% & F & \% & F & \% & F & \% \\
\hline Printing Shops & 21 & 72.4 & 4 & 13.8 & 4 & 13.8 & 29 & 100 \\
\hline Supermarkets & 18 & 53 & 12 & 35 & 4 & 12 & 34 & 100 \\
\hline Barbering & 14 & 50 & 6 & 20 & 8 & 30 & 28 & 100 \\
\hline Hairdressing & 23 & 85 & 0 & 0.00 & 4 & 15 & 27 & 100 \\
\hline Milling & 0 & 0.00 & 9 & 100 & 0 & 0.00 & 9 & 100 \\
\hline Food Vendors & 9 & 56.25 & 2 & 12.5 & 5 & 31.25 & 16 & 100 \\
\hline Cold Stores & 0 & 0.00 & 9 & 100 & 0 & 0.00 & 9 & 100 \\
\hline
\end{tabular}

Source: Field Survey, 2018

\subsection{Effectiveness of the coping mechanism}

The recent load management posed numerous challenges to the smooth running of enterprises, which in turn has caused owners of the enterprises to adopt coping mechanisms such as retrenchment of workers, reducing workers, salaries, working at night and the use of generators. In trying to establish how effective these coping mechanisms had been to smooth operation of the enterprises in the study area, the researchers enquired from the owners the extent to which they would rate a measure as: not effective, less effective, neutral, effective or more effective. The study revealed that $72.4 \%, 53 \%, 50 \%, 85 \%$ and $56.25 \%$ of the printing shops, supermarkets, barbering shops, milling factories, and food vendors respectively operators who adopted the use of generators in times of power cut found this coping mechanism less effective. This is because their use of generators resulted in an increase in their expenditure, hence affecting their profit margins. Nevertheless, the study realized that the decisions of the enterprises to work at night and also reduce their salaries were considered to be less effective. Table 6,7 and 8 below give tabular representation of how effective the coping mechanisms were to the enterprises in the study area.

Table.6. Effectiveness of the coping mechanism (work at night)

\begin{tabular}{|l|l|l|l|l|l|l|l|l|l|l|l|}
\hline Firms & \multicolumn{2}{l|}{ Not Effective } & \multicolumn{2}{l|}{ Less Effective } & \multicolumn{2}{l|}{ Neutral } & \multicolumn{2}{l|}{ Effective } & \multicolumn{2}{l|}{ More Effective } \\
\hline & $\mathbf{F}$ & $\mathbf{\%}$ & $\mathbf{F}$ & $\mathbf{\%}$ & $\mathbf{F}$ & $\mathbf{\%}$ & $\mathbf{F}$ & $\mathbf{\%}$ & $\mathbf{F}$ & $\mathbf{\%}$ \\
\hline Printing Shops & 0 & 0.00 & 4 & 13.8 & 0 & 0.00 & 0 & 0.00 & 0 & 0.00 \\
\hline Supermarkets & 0 & 0.00 & 4 & 12 & 0 & 0.00 & 0 & 0.00 & 0 & 0.00 \\
\hline Barbering & 0 & 0.00 & 8 & 30 & 0 & 0.00 & 0 & 0.00 & 0 & 0.00 \\
\hline Hairdressing & 0 & 0.00 & 4 & 15 & 0 & 0.00 & 0 & 0.00 & 0 & 0.00 \\
\hline Milling & 0 & 0.00 & 0 & 0.00 & 0 & 0.00 & 0 & 0.00 & 0 & 0.00 \\
\hline Food Vendors & 0 & 0.00 & 5 & 31.25 & 0 & 0.00 & 0 & 0.00 & 0 & 0.00 \\
\hline Cold Stores & 0 & 0.00 & 0 & 0.00 & 0 & 0.00 & 0 & 0.00 & 0 & 0.00 \\
\hline
\end{tabular}

Source: Field Survey, 2018 
Table 7. Effectiveness of the coping mechanism (reduce workers' salaries)

\begin{tabular}{|l|l|l|l|l|l|l|l|l|l|l|l|}
\hline Firms & \multicolumn{2}{|l|}{ Not Effective } & \multicolumn{2}{l|}{ Less Effective } & \multicolumn{2}{l|}{ Neutral } & \multicolumn{2}{l|}{ Effective } & \multicolumn{2}{l|}{ More Effective } \\
\hline & $\mathbf{F}$ & $\mathbf{\%}$ & $\mathbf{F}$ & $\mathbf{\%}$ & $\mathbf{F}$ & $\mathbf{\%}$ & $\mathbf{F}$ & $\mathbf{\%}$ & $\mathbf{F}$ & $\mathbf{\%}$ \\
\hline Printing Shops & 0 & 0.00 & 4 & 13.8 & 0 & 0.00 & 0 & 0.00 & 0 & 0.00 \\
\hline Supermarkets & 0 & 0.00 & 12 & 35 & 0 & 0.00 & 0 & 0.00 & 0 & 0.00 \\
\hline Barbering & 0 & 0.00 & 6 & 20 & 0 & 0.00 & 0 & 0.00 & 0 & 0.00 \\
\hline Hairdressing & 0 & 0.00 & 0 & 0.00 & 0 & 0.00 & 0 & 0.00 & 0 & 0.00 \\
\hline Milling & 0 & 0.00 & 9 & 100 & 0 & 0.00 & 0 & 0.00 & 0 & 0.00 \\
\hline Food Vendors & 0 & 0.00 & 2 & 12.5 & 0 & 0.00 & 0 & 0.00 & 0 & 0.00 \\
\hline Cold Stores & 0 & 0.00 & 9 & 100 & 0 & 0.00 & 0 & 0.00 & 0 & 0.00 \\
\hline
\end{tabular}

Source: Field Survey, 2018

Table 8. Effectiveness of the coping mechanism (use of generators)

\begin{tabular}{|c|c|c|c|c|c|c|c|c|c|c|}
\hline \multirow[t]{2}{*}{ Firms } & \multicolumn{2}{|c|}{ Not Effective } & \multicolumn{2}{|c|}{ Less Effective } & \multicolumn{2}{|c|}{ Neutral } & \multicolumn{2}{|c|}{ Effective } & \multicolumn{2}{|c|}{$\begin{array}{l}\text { More } \\
\text { Effective }\end{array}$} \\
\hline & $\mathbf{F}$ & $\%$ & $\mathbf{F}$ & $\%$ & $\mathbf{F}$ & $\%$ & $\mathbf{F}$ & $\%$ & $\mathbf{F}$ & $\%$ \\
\hline Printing Shops & 0 & 0.00 & 21 & 72.4 & 0 & 0.00 & 0 & 0.00 & 0 & 0.00 \\
\hline Supermarkets & 0 & 0.00 & 18 & 53 & 0 & 0.00 & 0 & 0.00 & 0 & 0.00 \\
\hline Barbering & 0 & 0.00 & 14 & 50 & 0 & 0.00 & 0 & 0.00 & 0 & 0.00 \\
\hline Hairdressing & 0 & 0.00 & 23 & 85 & 0 & 0.00 & 0 & 0.00 & 0 & 0.00 \\
\hline Milling & 0 & 0.00 & 0 & 0.00 & 0 & 0.00 & 0 & 0.00 & 0 & 0.00 \\
\hline Food Vendors & 0 & 0.00 & 9 & 56.25 & 0 & 0.00 & 0 & 0.00 & 0 & 0.00 \\
\hline Cold Stores & 0 & 0.00 & 0 & 0.00 & 0 & 0.00 & 0 & 0.00 & 0 & 0.00 \\
\hline
\end{tabular}

Source: Field Survey, 2018

Table 9. Quantity of electricity consumed by the SMEs

\begin{tabular}{|c|c|c|c|c|c|c|c|c|c|c|c|c|c|c|}
\hline \multirow{2}{*}{ 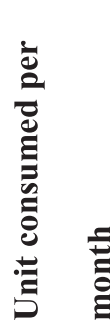 } & \multicolumn{2}{|c|}{ 些 } & \multicolumn{2}{|c|}{ 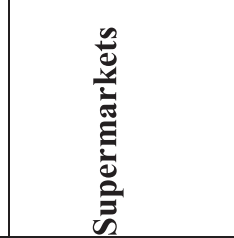 } & \multicolumn{2}{|c|}{ 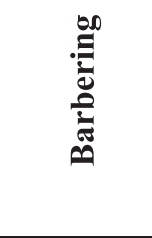 } & \multicolumn{2}{|c|}{ 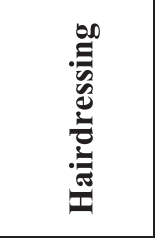 } & \multicolumn{2}{|c|}{ 郎 } & \multicolumn{2}{|c|}{ 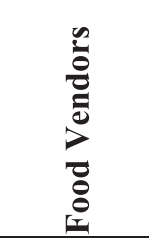 } & \multicolumn{2}{|c|}{$\begin{array}{l}\frac{0}{0} \\
\frac{0}{0} \\
\frac{0}{0} \\
\dot{0}\end{array}$} \\
\hline & $\mathbf{F}$ & $\%$ & F & $\%$ & $\mathbf{F}$ & $\%$ & $\mathbf{F}$ & $\%$ & $\mathbf{F}$ & $\%$ & $\mathbf{F}$ & $\%$ & $\mathbf{F}$ & $\%$ \\
\hline $0-50$ & 4 & 12.5 & 0 & 0.00 & 17 & 60 & 11 & 40 & 0 & 0.00 & 5 & 32 & 0 & 0.00 \\
\hline $51-300$ & 20 & $\begin{array}{l}68.7 \\
5\end{array}$ & 23 & 68.4 & 11 & 40 & 16 & 60 & 3 & 33.3 & 11 & 68 & 9 & 100 \\
\hline $300-600$ & 5 & $5^{18.7}$ & 11 & 31.6 & 0 & 0.00 & 0 & 0.00 & 6 & 66.7 & 0 & 0.00 & 0 & 0.00 \\
\hline $600+$ & 0 & 0.00 & 0 & 0.00 & 0 & 0.00 & 0 & 0.00 & 0 & 0.00 & 0 & 0.00 & 0 & 0.00 \\
\hline
\end{tabular}

Source: Field Survey, 2018

From table $9,100 \%$ of cold stores consumed between $51-300$ units, $68.42 \%$ of supermarket consumed 51 to 300 whiles $31.58 \%$ consumed 300 to 600 units per month. Also, $68 \%$ of food vendors consumed 51 to 300 units whereas $32 \%$ consumed 0 to 50 units. The study also identifies that $68.75 \%$ of the printing press consumed 51 to 300 units of electricity. $12.50 \%$ and $18.75 \%$ consume between 0 to 50 units and 300 to 600 units respectively. Hair dressing which constitutes $60 \%$ consumed 51 to 300 units and the remaining $40 \%$ consumed 0 to 50 units. It was noted that $40 \%$ of the barbering shop consumed 51 to 300 units with the $60 \%$ of them consuming 0 to 50 units.

4.6 Assessment of their perceptive about the expenditure incurred on electricity

The owners were also asked to indicate how they would assess their monthly expenditure on the use of electricity in day to day running of their respective businesses. The study revealed that all the printing presses, hairdressing and milling operators found their expenditure on electricity to be expensive. Similarly, 55.56\% and $80 \%$ of the food vendors and barbers respectively considered the tariffs they paid as expensive. Also, most of the supermarket operators, $78.94 \%$ and all the cold stores operators indicated that the expenditure they incur was very expensive. Further, the study showed that $21.05 \%$ of supermarkets and $44.4 \%$ of food vendors found their 
expenditure on electricity to be moderate. The study also identified that the perceptions of the firms about the expenditure they incurred were greatly influenced by the amount of the electricity they consume. From the analysis of the data gathered, it is obvious that all the small enterprises perceived to have their electricity tariffs expensive (See Figure 3).

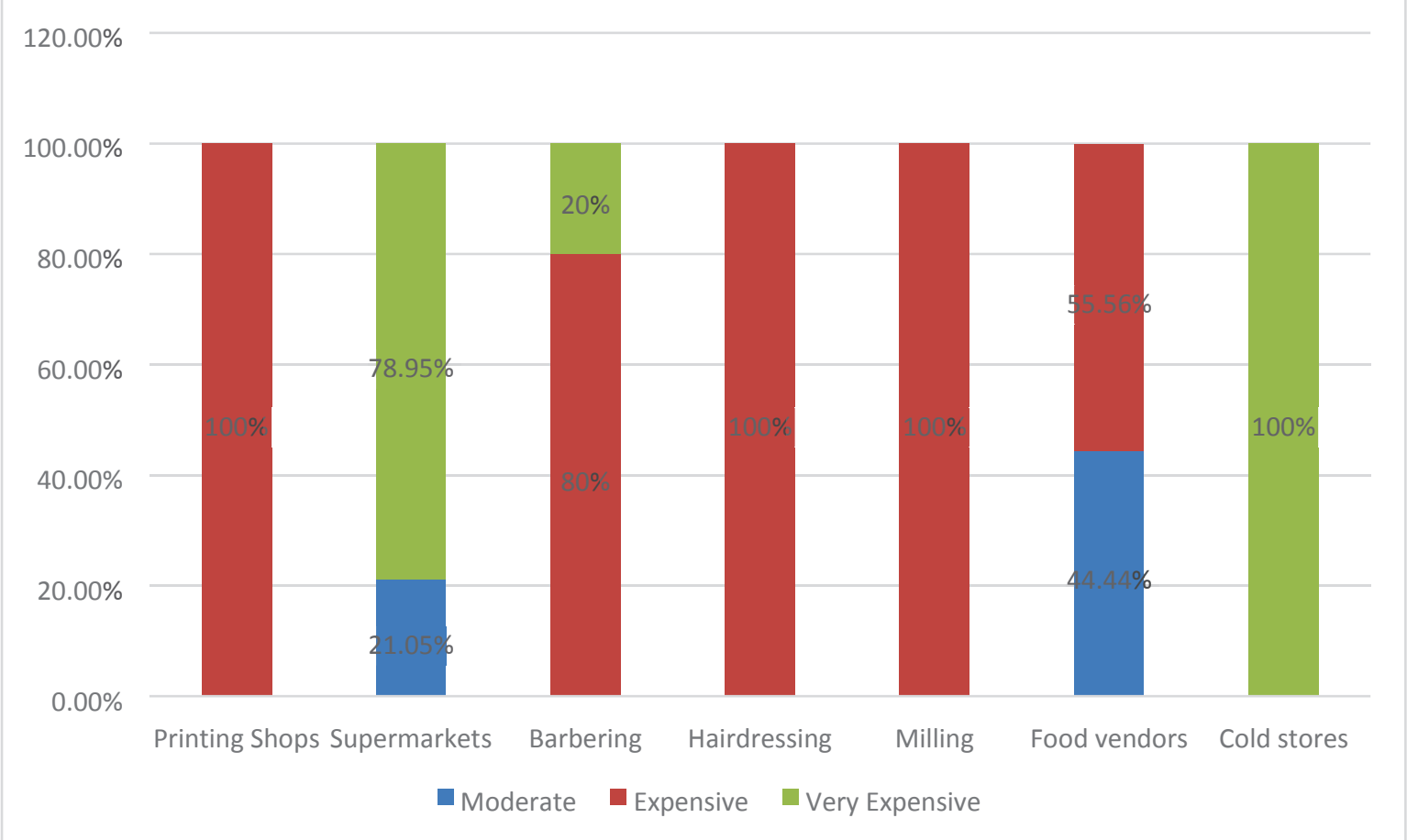

Figure 3. Assessment of their perceptive about the expenditure incurred on electricity

Source: Field Survey, 2018

\subsection{Effect of the coping mechanism on the profitability of SMEs}

Profit as the major motive of every entrepreneur will determine the ability of the respective entrepreneur to afford the proposed coping mechanisms during the electricity load management period. Based on this premise, the study assessed the profit margins of the enterprises by first examining their total expenditure and revenue and then their profit margins. The total average monthly expenditure for the barbering shop operators was estimated at $\mathrm{GH} \notin 857.36$ as indicated in table 10. The total monthly expenditure comprised inputs raw materials and barbers' salaries, taxes and tariffs. On the other hand, their estimated total monthly revenue averaged GH $\notin 2449.82$ as indicated in the table. This revealed an average monthly profit of GHф1592.46.

Again, the average total monthly production cost for the supermarket owners was GH $\varnothing 1943.56$ as indicated in table 12. The expenditure components also included the cost of inputs and stocks, transport and taxes. On the other hand, the average total monthly revenue was estimated at GH\&2650.85. The revenue and expenditure pattern for the supermarket revealed an average monthly profit of GHф707.29. Also, the monthly expenses incurred by the milling factories averaged

GH $\notin 1251$. Their expenditure covered inputs (labour), utility tariffs and taxes. The milling factories earned an average total monthly revenue of $\mathrm{GH} \phi 2253$. The expenditure and revenue patterns of the grinding millers revealed an average monthly profit of $\mathrm{GH} \phi 1002$.

The hair dressers averaged monthly expenditure, average monthly revenue and total monthly profit are GHф1102.56, GHф2160.22 and GHф1057.66 respectively as shown in table 10 . The printing shop owners incurred a total monthly averaged expenditure of $\mathrm{GH} \not 1164.62$ that comprises of inputs such as papers, inks, pins and electricity. The expenditure and revenue pattern of the printing shops revealed a monthly profit of $\mathrm{GH} \notin 1174.76$. The total expenditure of the cold stores was estimated at GH $\varnothing 1919$ including cost of stock, salaries, taxes and electricity tariffs. Their average monthly revenues and losses are GHф1529.33 and GH $\notin 389.67$ respectively. The tables below give the illustration of the effect of the coping mechanism on the profitability of SMEs in Madina. 
Table 10. Effect of the coping mechanism on the profitability of SMEs: Expenditure of the SMEs

\begin{tabular}{|c|c|c|c|c|c|c|c|c|c|c|c|c|c|c|}
\hline \multirow{2}{*}{$\begin{array}{l}\text { Expenses } \\
\text { (Amount } \\
\text { in } \mathrm{GH} \phi \text { ) }\end{array}$} & \multicolumn{2}{|c|}{$\begin{array}{c}\text { Cold } \\
\text { Stores }\end{array}$} & \multicolumn{2}{|c|}{ Supermarkets } & \multicolumn{2}{|c|}{$\begin{array}{c}\text { Food } \\
\text { Vendors }\end{array}$} & \multicolumn{2}{|c|}{ Printing } & \multicolumn{2}{|c|}{ Milling } & \multicolumn{2}{|c|}{$\begin{array}{c}\text { Hair } \\
\text { Dressing }\end{array}$} & \multicolumn{2}{|c|}{ Barbering } \\
\hline & $\mathbf{F}$ & $\%$ & $\mathbf{F}$ & $\%$ & $\mathbf{F}$ & $\%$ & $\mathbf{F}$ & $\%$ & $\mathbf{F}$ & $\%$ & $\mathbf{F}$ & $\%$ & $\mathbf{F}$ & $\%$ \\
\hline $500-1000$ & 0 & 0.00 & 0 & 0.00 & 11 & 66.67 & 16 & 56.25 & 0 & 0.00 & 15 & 54.00 & 22 & 80 \\
\hline $1001-1501$ & 0 & 0.00 & 12 & 36.80 & 3 & 22.22 & 4 & 12.50 & 9 & 100.00 & 5 & 20.00 & 6 & 20 \\
\hline $1502-2002$ & 6 & 66.67 & 7 & 21.05 & 2 & 11.11 & 7 & 25.00 & 0 & 0.00 & 7 & 26.00 & 0 & 0.00 \\
\hline $2003-2503$ & 3 & 33.33 & 5 & 15.79 & 0 & 0.00 & 2 & 6.25 & 0 & 0.00 & 0 & 0.00 & 0 & 0.00 \\
\hline 2504-3004 & 0 & 0.00 & 10 & 26.31 & 0 & 0.00 & 0 & 0.00 & 0 & 0.00 & 0 & 0.00 & 0 & 0.00 \\
\hline MEAN & \multicolumn{2}{|c|}{1919} & \multicolumn{2}{|c|}{1943.56} & \multicolumn{2}{|c|}{969.19} & \multicolumn{2}{|c|}{1164.62} & \multicolumn{2}{|c|}{1251} & \multicolumn{2}{|c|}{1102.56} & \multicolumn{2}{|c|}{857.36} \\
\hline
\end{tabular}

Source: Field Survey, 2018

Table 11. Revenues of the enterprises

\begin{tabular}{|c|c|c|c|c|c|c|c|c|c|c|c|c|c|c|}
\hline \multirow{2}{*}{$\begin{array}{l}\text { Revenues } \\
\text { (Amount } \\
\text { in } \mathrm{GH} \phi)\end{array}$} & \multicolumn{2}{|c|}{$\begin{array}{c}\text { Cold } \\
\text { Stores }\end{array}$} & \multicolumn{2}{|c|}{ Supermarkets } & \multicolumn{2}{|c|}{$\begin{array}{c}\text { Food } \\
\text { Vendors }\end{array}$} & \multicolumn{2}{|c|}{ Printing } & \multicolumn{2}{|c|}{ Milling } & \multicolumn{2}{|c|}{$\begin{array}{c}\text { Hair } \\
\text { Dressing }\end{array}$} & \multicolumn{2}{|c|}{ Barbering } \\
\hline & $\mathbf{F}$ & $\%$ & $\mathbf{F}$ & $\%$ & $\mathbf{F}$ & $\%$ & $\mathbf{F}$ & $\%$ & $\mathbf{F}$ & $\%$ & $\mathbf{F}$ & $\%$ & $\mathbf{F}$ & $\%$ \\
\hline $500-1000$ & 0 & 0.00 & 0 & 0.00 & 0 & 0.00 & 0 & 0.00 & 0 & 0.00 & 0 & 0.00 & 0 & 0.00 \\
\hline $\begin{array}{l}1001- \\
1501\end{array}$ & 4 & 0.00 & 0 & 0.00 & 0 & 0.00 & 0 & 0.00 & 0 & 0.00 & 0 & 0.00 & 0 & 0.00 \\
\hline $\begin{array}{l}1502- \\
2002\end{array}$ & 5 & 0.00 & 0 & 0.00 & 0 & 0.00 & 0 & 0.00 & 0 & 0.00 & 5 & 20.00 & 0 & 0.00 \\
\hline $\begin{array}{l}2003- \\
2503\end{array}$ & 0 & 0.00 & 7 & 21.05 & 4 & 22.22 & 24 & 81.25 & 9 & 100.00 & 22 & 80.00 & 17 & 60.00 \\
\hline $\begin{array}{l}2504- \\
3004\end{array}$ & 0 & 100.00 & 27 & 78.95 & 12 & 77.78 & 5 & 18.75 & 0 & 0.00 & 0 & 0.00 & 11 & 40.00 \\
\hline MEAN & \multicolumn{2}{|c|}{1529.33} & \multicolumn{2}{|c|}{2650.85} & \multicolumn{2}{|c|}{2628.75} & \multicolumn{2}{|c|}{2339.38} & \multicolumn{2}{|c|}{2253} & \multicolumn{2}{|c|}{2160.22} & \multicolumn{2}{|c|}{2449.82} \\
\hline
\end{tabular}

Source: Field Survey, 2018

Table 12. Average monthly profit of the enterprise

\begin{tabular}{lcc}
\hline Firm & Average Monthly Profit & Rank in Terms of Profit \\
\hline Food vendors & 1659.56 & 1st \\
Barbering & 1592.46 & 2nd \\
Printing shops & 1174.76 & $3 \mathrm{rd}$ \\
Hair dressing & 1057.66 & 4 th \\
Milling & 1002 & 5 th \\
Super market & 707.29 & 6 th \\
Cold Stores & -389.67 & 7 th \\
\hline
\end{tabular}

Source: Field Survey, 2018

\subsection{Alternative source of electricity}

Owing to the fact that interrupted power supply has adverse effects on the operations of the enterprises, the researchers decided to ascertain the options used by them during periods of interrupted power supply. From table 13, all the milling factories and cold stores depend solely on electricity supplied by ECG. In the same vein, $43.75 \%, 47 \%$, and $50 \%$ of food vendors, supermarkets, and barbering shops have no alternative sources of electricity in the event of power failure. This means that food vendors, barbering shops and supermarkets are affected in their wait for power to be restored when there are power cuts. However, $72.4 \%$ of the printing shop operators, $53 \%$ supermarkets, $50 \%$ barbers, $85 \%$ of the hair dressers, and $56.25 \%$ of the food vendors used generators to ensure the continuous supply of electricity. 
Table 13. Alternative Source of Electricity

\begin{tabular}{lllllll}
\hline Firms & None & \multicolumn{2}{l}{ Use of generators } & \multicolumn{2}{c}{ Total } & F \\
& F & $\mathbf{\%}$ & F & $\mathbf{\%}$ & F & 100 \\
\hline Printing Shops & 8 & 27.6 & 21 & 72.4 & 29 & 100 \\
Supermarkets & 16 & 47 & 18 & 53 & 34 & 100 \\
Barbering & 14 & 50 & 14 & 50 & 28 & 100 \\
Hairdressing & 4 & 15 & 23 & 85 & 27 & 100 \\
Milling & 9 & 100 & 0 & 0.00 & 9 & 100 \\
Food Vendors & 7 & 43.75 & 9 & 56.25 & 16 & 100 \\
Cold Stores & 9 & 100 & 0 & 0.00 & 9 & \\
\hline
\end{tabular}

Source: Field Survey, 2018

\subsection{Conclusions, findings and recommendations}

The evidence from the study indicates that the recent load management is having adverse effect on the profitability of many SMEs since they highly depend on electricity for their operations. It is therefore incumbent on the government to intervene with remedial measures and policies which will ensure reliable and regular supply of electricity for small-scale businesses to flourish. It was also clear from the findings that the enterprises in event of load management adopted measures to help them cope with the adverse effect of load management. These coping mechanisms such as reduction of workers' salaries, retrenchment of workers, working at night and use of generators made workers worse off since those measures affected their living standards. There is the need for government to provide subsidy on reliable and alternative source of electricity like solar energy so that enterprise can afford to buy and use them in their operations.

The study noticed that the cold stores operators were highly affected by the recent load management as all of them on the average incurred a loss of GHф 389.67 per month. Even though supermarkets, barbering shops, hair dressing salons, milling factories, food vendors, and printing shops had a decline in their profit margin, it was identified that the operators of cold stores ran at loss. The study also discovered that, in the mist of the load management, the enterprises adopted these coping mechanisms such as retrenching workers, working at night, using generators, and reducing workers' salaries to minimize the adverse effects of the recent load management on the smooth operations. The researchers also find out that, $56 \%$ of the SMEs make use of generators in the face of the recent load management which turn to add up to the expenses of the SMEs, hence decrease in their profit margin.

Owners of SMEs also agreed to the assertion that the current load management had adverse effects on the output, labor, input, plant and equipment of the SMEs under study and as a result, they had suffered decline in their relative profit margin. The use of generators reported less effective in resolving the challenges posed by load management due to high fuel price.

\subsection{Recommendations:}

Based on the findings, Government should invest in solar energy to be a substitute power supply to the country during the dry season where there is constant sunlight which obviously will also reduce pressure on electricity plants. During this time, the broken and old plants at the Volta River Authority (VRA) can be fixed and replaced by the Electricity Company of Ghana (ECG) so that they can work effectively during raining season where the sunshine would not be available to power the solar. Government should also subsidize for fuel in other to reduce the cost of the enterprises using the generators in time of interrupted power supply. Volta River Authority (VRA) should also explore other energy technologies such as the thermal energy and the wind energy in restoring constant supply of power so as to ensure continuity of business operations. A strong research and development centre should be set up to deal with researches that will provide alternative power supply to the country whenever the Akosombo dam does not have enough water to supply power to the whole country.

\section{References}

Adenikinju, A. F. (2005). Analysis of the cost of infrastructure failures in a developing economy: The case of the electricity sector in Nigeria (Vol. 148). African Economic Research Consortium.

African Development Bank (2005) African Economic Outlook 2004/2005: Recent Economic Trends in Africa and Prospects for 2006. African Development Bank, Abidjan Discussion Paper

Agyedu, G.D., Donkor, F. and Obeng, S. (2007). Teach Yourself Research Methods, University of Education, Winneba

Alam, A. (2013). Electric power consumption, foreign direct investment and economic growth. A comparative study of India and Pakistan. World Journal of Science, Technology and Sustainable Development, 10(1), $55-65$ 
Amponsah, O. (2010): Towards a reliable and sustainable supply of electricity for Micro and Small-scale industries in Kumasi. An unpublished thesis submitted to the school of Graduate Studies, Kwame Nkrumah University of Science and Technology in partial fulfilment of the awards of a Master of Science Degree in Development Policy and Planning (June, 2010)

Anderson, P. L., \& Geckil, I. K. (2003). Northeast Blackout Likely to Reduce US Earnings by \$6.4 Billion. Anderson Economic Group Working Paper 2003-2.

Aremu, M. A., \& Adeyemi, S. (2011). Small and Medium Scale Enterprises as a Survival Strategy for Employment Generation in Nigeria. Journal of Sustainable Development, 4 (1), 200 - 206.

Arinaitwe, J. K. (2006). Factors constraining the growth and survival of small-scale businesses: a developing countries analysis. Journal of American Academy of Business, 8(2), 167178.

Amoako-Tuffour, J., \& Armah, B. K. (Eds.). (2008). Poverty reduction strategies in action: perspectives and lessons from Ghana. Lexington Books.

Barney, J., (1991). Firm Resources and Sustained Competitive Advantage. Journal of Management, 17(1), pp.99120.

Been, M., and Goldin, E. (1997). Priority pricing in electricity supply: An application for Israel. Resources and Energy Economics, 19(3), 175-189,

Bellarmine, G. T., \& Arokiaswamy, N. S. S. (1999). Load Management. Wiley Encyclopaedia of Electrical and Electronics Engineering.

Burlando, A. (2010). The Impact of Electricity on Work and Health: Evidence from a Blackout in Zanzibar.

Caves, D. W., Herriges, J. A., \& Windle, R. J. (1992). The cost of electric power interruptions in the industrial sector: Estimates derived from interruptible service programs. Land Economics, 49-61.

Centre for Policy Analysis. (2007). The Energy Crisis and Growth Performance of the Economy of Ghana Selected Economic Issues. CEPA Issue Paper No. 15.

Concha Velásquez, J. R., \& Pichler, B. (2010). China's increasing economy and the impacts on its energy strategy. Estudios Gerenciales, 26(117), 131-144.

Confederation of Tanzania Industries (CTI). (2011). Challenges of Unreliable Electricity Supply to Manufacturers in Tanzania, A Policy Research Paper Submitted to Energy Sector Stakeholders in Advocacy for Ensured Reliable Electricity Supply to Tanzanian Manufacturers.

Energy Commission of Ghana (2006a). Strategic National Energy Plan 2006-2020, Main report.

Energy Commission of Ghana (2006b). Strategic National Energy Plan 2006-2020, Annex Four of Four. Energy Supply of the Economy Wood fuels and Renewables. energy.lbl.gov/node/147

Fobil, J.N., \& Atuguba, R.A. (2004). Ghana: Migration and the African urban complex. Globalization and Urbanization in Africa, 249-269.

Gabrielian, V. (1999). Qualitative research methods: An overview. Handbook of research methods in public administration, 167-205.

Government of Ghana (2004) White Paper on the Report of the Education Reform Review Committee, Ministry of Education, Youth and Sports. Accra Ghana.

Huang, E. T., \& Bell, W. R. (2004). An empirical study on using ACS supplementary survey data in SAIPE state poverty models. In 2004 Proceedings of the American Statistical Association (pp. 3677-3684).

Institute of Statistical, Social and Economic Research. (2005). The Guide to Electric Power, first edition, Resource Centre for Energy Economics and Regulation, University of Ghana, Legon - Accra. International Perspective. Georgia Tech Ivan Allen College School of Public Policy Work paper 45.

Irjayanti, M., \& Azis, A. M. (2012). Success factors of fast-moving goods of small medium enterprises in Indonesia'. Proceeding at 2nd Annual Summit on Business and Entrepreneurial Studies.

Irjayanti, M., \& Azis, A. M. (2013). Knowledge Management for Banking Industry Continuous Improvement. Jurnal Teknologi, 64(3).

Juei Wang, E. (2002). Outage costs and strategy analysis for hi-tech industries: A fuzzy multiple goal approach. International Journal of Quality \& Reliability Management, 19(8/9), 1068-1087.

Jyoti, R., Ozbafli, A., \& Jenkins, G. P. (2006). The Opportunity Cost of Electricity Outages and Privatization of Substations in Nepal. Available at SSRN 898127.

Kapepiso, F. M. (2015). Investment policy and the role of the banking sector in financing small and medium enterprises (Doctoral dissertation).

Kayanula, D. \& Quartey, P. (2000). "The Policy Environment for Promoting Small and Medium sized Enterprises in Ghana and Malawi", an article published in Finance and Development Research Program working paper series 15, IDPM, University of Manchester.

Kumasi Metropolitan Assembly. (2010). Medium Term Development Plans, 2010 - 2013, unpublished development plan.

Kumekpor, T. K. (2002). Research methods and techniques of social research. Son Life Press \& Services.

Lee, K. S., \& Anas, A. (1992). Costs of deficient infrastructure: The case of Nigerian manufacturing. Urban 
Studies, 29(7), 1071-1092.

Lineweber,D., and McNuulty, S. (2001). The cost of power disturbances to industrial \& digital economy companies. EPRI.

Ministry of Energy Ghana. (2010). National Energy Policy. Retrieved 19/12/2015 http://ghanaoilwatch.org/images/laws/national_energy_policy.pdf

Nachmias, C. F., \& Nachmias, D. (1996). Research Methods in the Social Sciences, New York: NDPC (2008). Draft Long-Term Development Plan, Vol. 1, Towards a Development Policy Framework, Unpublished.

Rajan, G. G. (2003). Optimizing energy efficiencies in industry. New York: McGraw-Hill.

Reijonen, H. and Komppula R, (2007). Perception of Success and its effect on small firm performance, Journal of Small Business and Enterprise development Vol. 14 No. 4, 689 - 701.

Sambo, A. S. (2005). Renewable Energy for Rural Development: The Nigerian Perspective ${ }^{e e}$ in ISSESCO Science and Technology Vision, Volume 1,pg 12 - 22.

Steel, W.F., and L.M. Webster, (1991). Small Enterprises under Adjustment in Ghana. World Bank Technical Paper No. 138. The World Bank, Washington, D.C.

Tambunan, T. (2004). Women Entrepreneurs in Indonesia: their main constraints and reasons. A Historical Development of Entrepreneurship in the Cameroon.

Tacoli, C, and Satterhwaite, D., (2003). The urban part of rural development: the role of small and intermediate urban centres in rural and regional development and poverty reduction.

Uchendu, O.A., (1993). The economic cost of electricity outages: Evidence from a sample study of industrial and commercial firms in the Lagos area of Nigeria. CBN Economic and

Financial Review, 31. USAID. Energy and Small and Medium Enterprises

UNCTAD (2001) Growing Micro and Small Enterprises in LDCs: The "missing middle" in LDCs: why micro and small enterprises are not growing. Geneva, UNCTAD/ITE/TEB/5.

Wangwe, S. M. (1999) Micro and Small Enterprises Development and Employment Implications: Review for Current Status and Prospects, Economic and Social Research Foundation (ESRF). 